\title{
Cascadable Current-Mode First-Order All-Pass Filter Based on Minimal Components
}

\author{
Jitendra Mohan ${ }^{1}$ and Sudhanshu Maheshwari ${ }^{2}$ \\ ${ }^{1}$ Department of Electronics \& Communication Engineering, Jaypee Institute of Information Technology, Noida 201304, India \\ ${ }^{2}$ Department of Electronics Engineering, Z.H. College of Engineering and Technology, Aligarh Muslim University, \\ Aligarh 202002, India
}

Correspondence should be addressed to Jitendra Mohan; jitendramv2000@rediffmail.com

Received 11 March 2013; Accepted 26 May 2013

Academic Editors: D. S. Budimir and K. Dejhan

Copyright (C) 2013 J. Mohan and S. Maheshwari. This is an open access article distributed under the Creative Commons Attribution License, which permits unrestricted use, distribution, and reproduction in any medium, provided the original work is properly cited.

\begin{abstract}
A novel current-mode first-order all-pass filter with low input and high output impedance feature is presented. The circuit realization employs a single dual-X-second-generation current conveyor, one grounded capacitor, and one grounded resistor, which is a minimum component realization. The theoretical results are verified using PSPICE simulation program with TSMC $0.35 \mu \mathrm{m}$ CMOS process parameters.
\end{abstract}

\section{Introduction}

Current-mode circuit design using current conveyor has received a considerable attention owning to its potential advantages such as wider dynamic range, greater linearity, wide bandwidth, simple circuitry, and low power consumption [1]. Considering these advantages of current conveyor, recently several current mode first-order all-pass filters employing different types of current conveyor such as second-generation current conveyor [2-4], four terminal floating nullor [5], third-generation current conveyor [6], differential voltage current conveyor $[7,8]$, current differencing buffered amplifier [9], current operational amplifier [10], and dual-X second-generation current conveyor $[11,12]$ have been reported. These reported filters reveal some useful features depending on the individual topology as summarized in Table 1. The comparison between the proposed circuit and the previously reported circuits is based on the use of number of active elements, number of grounded passive components, and low input and high output impedance feature(s). In general, the input impedance should be lower in comparison to the output impedance to avoid loading problem while cascading such current-mode circuits to form larger system.

In this paper, a novel cascadable current-mode (CM) first-order all-pass filter is proposed. The circuit uses a
dual-X second generation multioutput current conveyor (DX-MOCCII), a grounded resistor, and a grounded capacitor, which is ideal for IC implementation. The circuit offers low-input impedance and high-output impedance feature and also free from matching constraints. Nonideal gain and parasitic effects of the DX-MOCCII on the transfer function of the proposed filter are also analysed.

\section{The Proposed Circuit}

Dual-X second-generation current conveyor [13] is a useful and versatile active element, which has found several applications in analog signal processing [14-18]. The DXMOCCII symbol is shown in Figure 1 and is characterized by the following port relationships:

$$
\left[\begin{array}{c}
I_{Y} \\
V_{X+} \\
V_{X-} \\
I_{Z 1+} \\
I_{Z 2+} \\
I_{Z 1-} \\
I_{Z 2-}
\end{array}\right]=\left[\begin{array}{ccc}
0 & 0 & 0 \\
1 & 0 & 0 \\
-1 & 0 & 0 \\
0 & 1 & 0 \\
0 & -1 & 0 \\
0 & 0 & 1 \\
0 & 0 & 1
\end{array}\right]\left[\begin{array}{c}
V_{Y} \\
I_{X+} \\
I_{X-}
\end{array}\right],
$$

where the suffixes refer to the respective terminals. The active element is characterized by high input impedance at 
TABLE 1: Comparison of various current-mode all-pass filters.

\begin{tabular}{|c|c|c|c|c|c|c|c|}
\hline References & $\begin{array}{c}\text { No. of active } \\
\text { elements }\end{array}$ & $\begin{array}{c}\text { Single active } \\
\text { element }\end{array}$ & $\begin{array}{l}\text { No. of resistors } \\
\text { and capacitors }\end{array}$ & $\begin{array}{c}\text { All-grounded } \\
\text { passive elements }\end{array}$ & $\begin{array}{l}\text { Low input } \\
\text { impedance }\end{array}$ & $\begin{array}{l}\text { High output } \\
\text { impedance }\end{array}$ & $\begin{array}{c}\text { Component } \\
\text { matching constraint }\end{array}$ \\
\hline Higashimura and Fukui [2] & 1-CCII & Yes & 4 & No & No & Yes & Yes \\
\hline Higashimura [5] & 1-FTFN & Yes & 3 & No & No & No & Yes \\
\hline Toker et al. [9] & 1-CDBA & Yes & 2 & No & No & Yes & No \\
\hline Maheshwari and Khan [6] & 1-CCIII & Yes & 2 & No & No & No & No \\
\hline Kilinç and Çam [10] & 1-COA & Yes & 2 & No & No & Yes & No \\
\hline Minaei and Ibrahim [7] & 1-DVCC & Yes & 3 & No & No & Yes & Yes \\
\hline Khan et al. [3] & 2-MOCCII & No & 2 & Yes & No & Yes & No \\
\hline Maheshwari [8] & 1-DVCC & Yes & 2 & Yes & No & Yes & No \\
\hline Minaei and Yuce [4] & 2-DOCCII & No & 2 & Yes & Yes & Yes & No \\
\hline Minaei and Yuce [11] & 1-DXCCII & Yes & 4 & Yes & No & Yes & Yes \\
\hline Beg et al. [12] & 1-DX-MOCCII & Yes & 4 & Yes & No & Yes & Yes \\
\hline Proposed Circuit & 1-DX-MOCCII & Yes & 2 & Yes & Yes & Yes & No \\
\hline
\end{tabular}

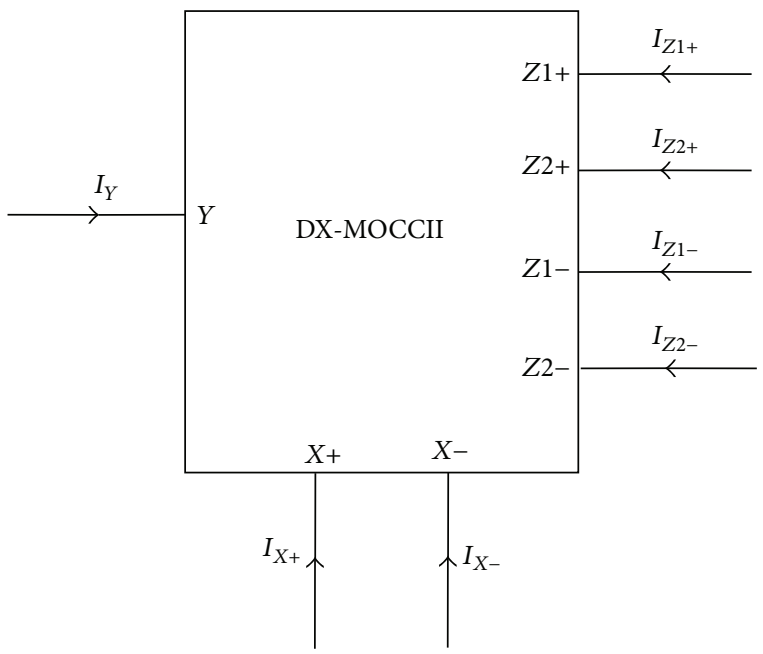

FIGURE 1: Symbol of DX-MOCCII.

the $Y$ terminal, high output impedance at the $Z 1+, Z 2+, Z 1-$, and $Z 2-$ terminals, and low impedance at the $X+$ and $X-$ terminals.

The proposed current-mode (CM) first-order all-pass filter employing a DX-MOCCII, a grounded capacitor, and a grounded resistor is shown in Figure 2. Routine analysis of the circuit, using (1), yields the following transfer function:

$$
\frac{I_{\text {out }}}{I_{\text {in }}}=-\left(\frac{s-(1 / C R)}{s+(1 / C R)}\right) \text {. }
$$

The frequency-dependent phase response of (2) is

$$
\Phi=-2 \tan ^{-1}(\omega R C)
$$

From (3), it can be seen that the proposed circuit can provide a phase shift between $0^{\circ}$ and $-180^{\circ}$ at output terminal $\left(I_{\text {out }}\right)$.

The salient features of the proposed circuit are the use of single active element, two grounded passive components, and providing low input and high output impedance. As all the passive components used are in grounded form, it is suitable for integrated circuit implementation and also reduces the associated parasitic effects [19].

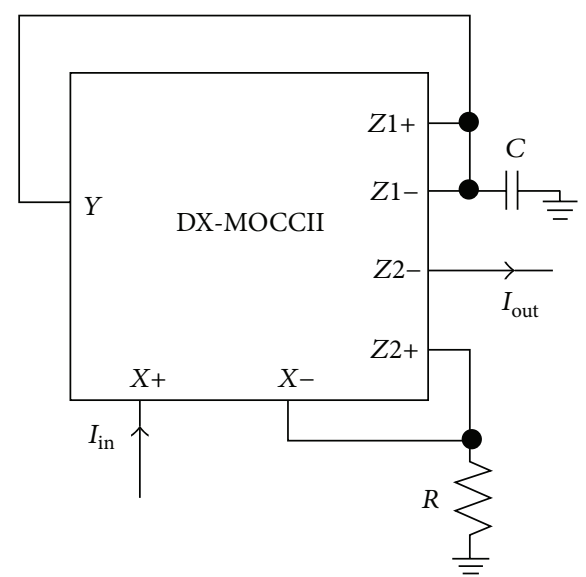

Figure 2: Proposed cascadable current-mode first-order all-pass filter.

By interchanging the resistor $(R)$ with a capacitor $(C)$ in Figure 2, an additional circuit can be derived from the proposed circuit. However, the use of capacitor at the $X-$ terminal degrades the high frequency operation [20].

\section{Nonideal Analysis and Parasitic Effects}

3.1. Non-Ideal Analysis. Taking the nonidealities of the DXMOCCII into account, the port relationship of the voltage and current terminals of the active element can be rewritten as

$$
\left[\begin{array}{c}
I_{Y} \\
V_{X+} \\
V_{X-} \\
I_{Z 1+} \\
I_{Z 2+} \\
I_{Z 1-} \\
I_{Z 2-}
\end{array}\right]=\left[\begin{array}{ccc}
0 & 0 & 0 \\
\beta_{1} & 0 & 0 \\
-\beta_{2} & 0 & 0 \\
0 & \alpha_{1} & 0 \\
0 & -\alpha_{2} & 0 \\
0 & 0 & \alpha_{3} \\
0 & 0 & \alpha_{4}
\end{array}\right]\left[\begin{array}{c}
V_{Y} \\
I_{X+} \\
I_{X-}
\end{array}\right]
$$

Here, $\alpha_{1}$ and $\alpha_{2}$ are the current transfer gains from $X+$ terminal to $Z 1+$ and $Z 2+$ terminals, $\alpha_{3}$ and $\alpha_{4}$ are the current transfer gains from $X$ - terminal to $Z 1$ - and $Z 2$ - terminals, 


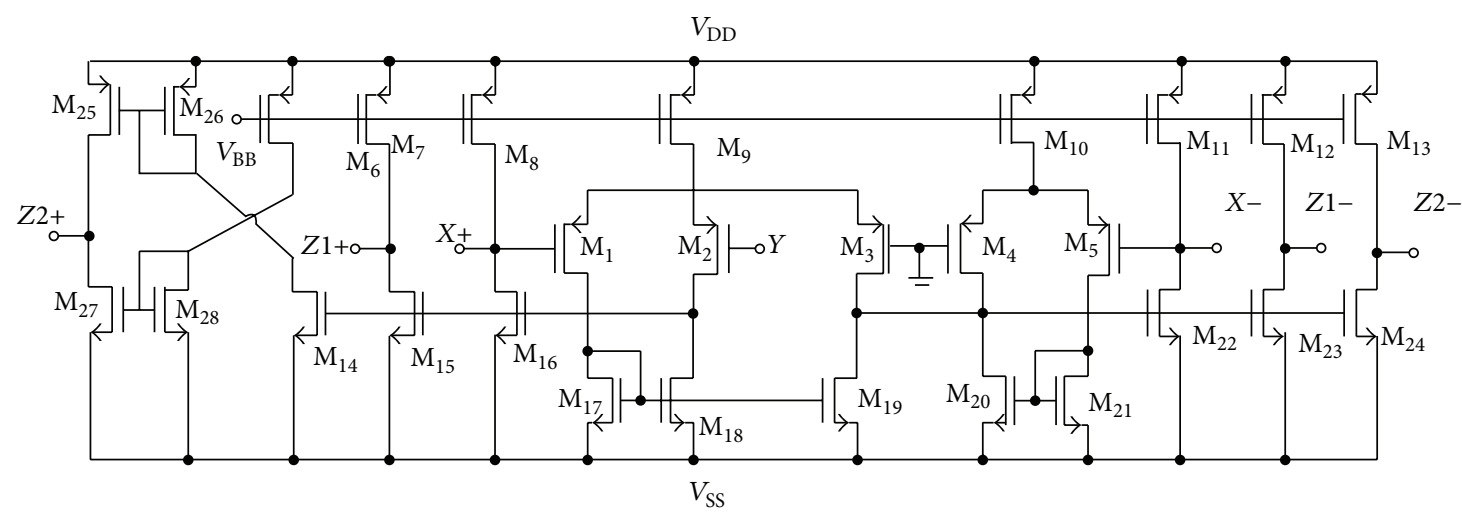

FIGURE 3: CMOS implementation of DX-MOCCII.

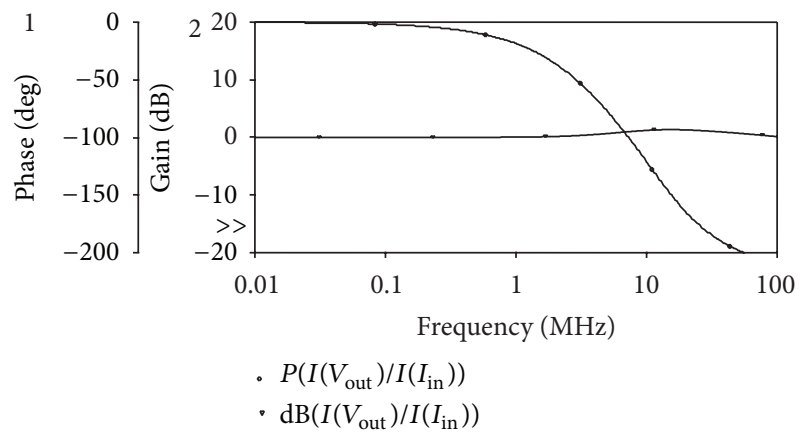

FIGURE 4: Simulated gain and phase responses of the all-pass filter.

respectively, and $\beta_{1}$ and $\beta_{2}$ are the voltage transfer gains from input to $X+$ and $X$ - terminals, respectively. More specifically, $\alpha_{1}=\left(1-\varepsilon_{1}\right), \alpha_{2}=\left(1-\varepsilon_{2}\right), \alpha_{3}=\left(1-\varepsilon_{3}\right), \alpha_{4}=(1-$ $\left.\varepsilon_{4}\right), \beta_{1}=\left(1-\delta_{1}\right)$, and $\beta_{2}=\left(1-\delta_{2}\right)$, where $\varepsilon$ is the current transfer error (tracking error) and $\delta$ is the voltage transfer error (tracking error) of the DX-MOCCII. However, these transfer gains differ from unity by the voltage and current tracking errors of the DX-MOCCII.

The proposed circuit is reanalyzed by taking the tracking errors of the nonideal MO-DXCCII into account, and the modified current transfer function is given as

$$
\frac{I_{\mathrm{out}}}{I_{\mathrm{in}}}=-\alpha_{2} \alpha_{4}\left(\frac{s-\left(\beta_{2} \alpha_{1} / C R \alpha_{2}\right)}{s+\left(\beta_{2} \alpha_{3} / C R\right)}\right) .
$$

Equation (5) reveals that the nonidealities do affect the filter gain and the pole frequency as well as the zero frequency. Assuming matched current transfer gains $\left(\alpha_{1}\right.$ and $\left.\alpha_{3}\right)$ the phase characteristics would not be affected. The sensitivities of pole frequency $\left(\omega_{0}\right)$ and gain $(H)$ with respect to active and passive components are derived from (5). These are as follows:

$$
\begin{aligned}
& S_{C, R}^{\omega_{o}}=-1, \quad S_{\alpha_{3}, \beta_{2}}^{\omega_{o}}=1, \quad S_{\alpha_{1}, \alpha_{2}, \alpha_{4}, \beta_{1}}^{\omega_{o}}=0 \text {, } \\
& S_{C, R}^{H}=0, \quad S_{\alpha_{1}, \alpha_{3}, \beta_{1}, \beta_{2}}^{H}=0, \quad S_{\alpha_{2}, \alpha_{4}}^{H}=1 .
\end{aligned}
$$

From the results, it is evident that the sensitivities are within unity in magnitude, thus ensuring a low sensitivity performance.
TABLE 2: Aspect ratios of the transistors.

\begin{tabular}{lcc}
\hline Transistors & $W(\mu \mathrm{m})$ & $L(\mu \mathrm{m})$ \\
\hline $\mathrm{M}_{1}-\mathrm{M}_{2}$ & 1.4 & 0.7 \\
$\mathrm{M}_{3}-\mathrm{M}_{5}$ & 2.8 & 0.7 \\
$\mathrm{M}_{17}-\mathrm{M}_{18}$ & 2.4 & 0.7 \\
$\mathrm{M}_{19}-\mathrm{M}_{21}$ & 4.8 & 0.7 \\
$\mathrm{M}_{6}-\mathrm{M}_{16}, \mathrm{M}_{22}-\mathrm{M}_{28}$ & 9.6 & 0.7 \\
\hline
\end{tabular}

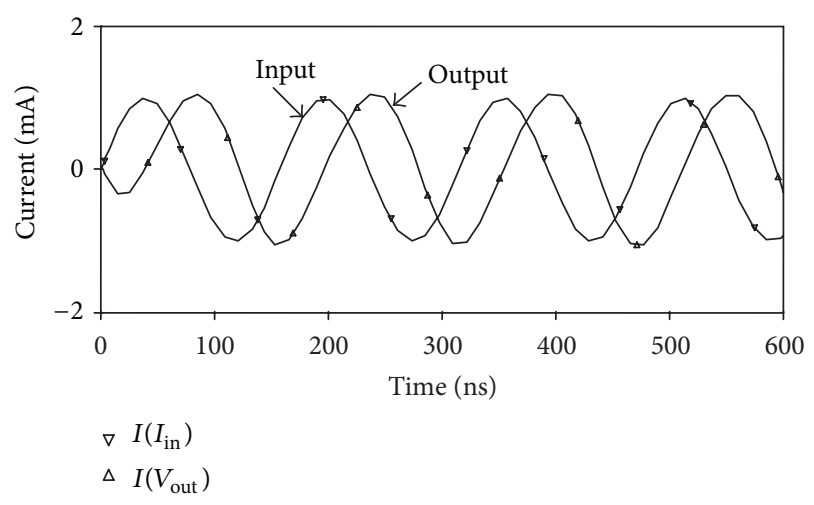

FIGURE 5: Time-domain input and output responses of all-pass filter.

3.2. Parasitic Effects. Next study is carried on the effect of device parasitics on the performance of the proposed circuit. The various parasitics are a low value parasitic serial resistance $R_{X}$ at $X$ the terminal $Y$ exhibits a high value parasitic resistance $R_{Y}$ in parallel with low value capacitor $C_{Y}$, and the terminals $Z$ exhibit a high value parasitic resistance $R_{Z}$ in parallel with low value capacitance $C_{Z}$. The main among these are the $Y$ and $Z$ terminals parasitic capacitances and the $X$ terminal's parasitic resistances. A reanalysis of the proposed circuit yields the modified transfer function as

$$
\frac{I_{\text {out }}}{I_{\text {in }}}=-\left(\frac{s R C^{\prime}-s R C_{Z 2+}-1}{s^{2} R R_{X} C^{\prime} C_{Z 2+}+s\left(R C^{\prime}+R_{X} C^{\prime}+R C_{Z 2+}\right)+1}\right),
$$

where $C^{\prime}=C+C_{Z 1-}+C_{Z 1+}$.

From (7), the effect of capacitance $C_{Z 2+}$ becomes nonnegligible at very high frequencies. Most of the parasitic 


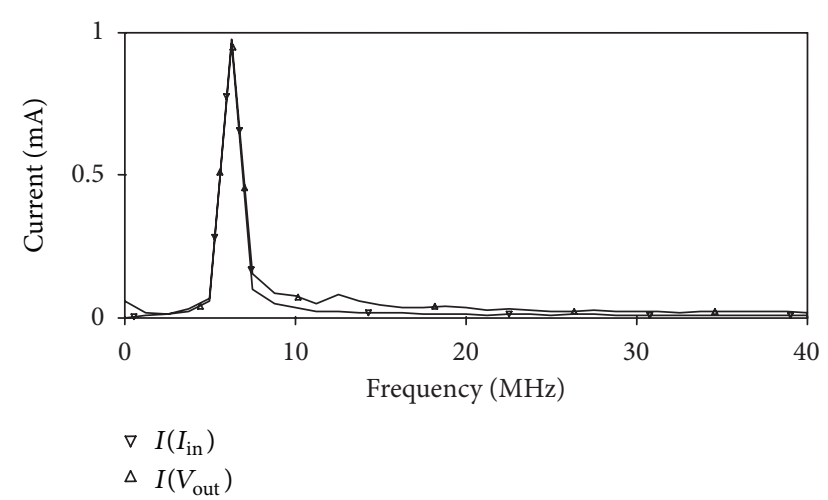

FIGURE 6: Fourier spectrum of the input and output.

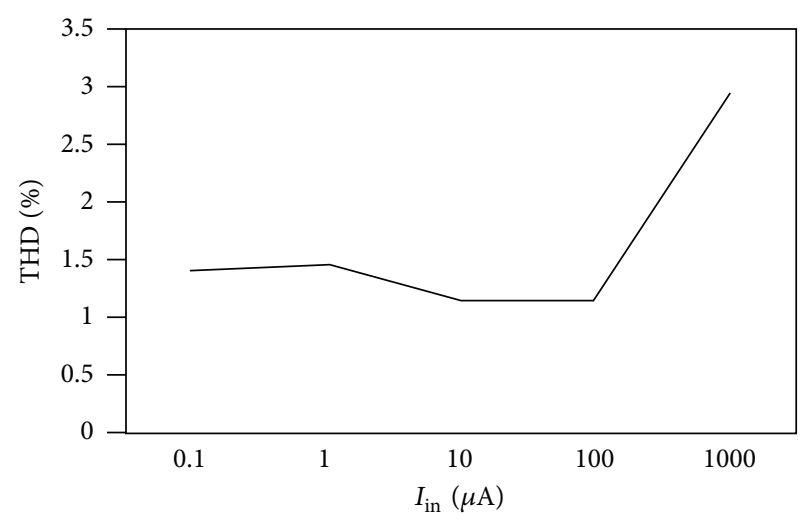

FIgURE 7: THD variation at output $\left(I_{\text {out }}\right)$ with sinusoidal signal amplitude at $6.36 \mathrm{MHz}$.

capacitances get absorbed with the external grounded capacitor, as are in shunt with it. Also the parasitic resistance gets absorbed with the external grounded resistor, as it is in series with it. Such a merger will cause a slight deviation in circuit parameters, which can be corrected by predistorting the passive element values used in the circuit.

\section{Simulation Results}

To demonstrate the performance of the proposed circuit, the PSPICE simulation program is used. In the simulation, the TSMC $0.35 \mu \mathrm{m}$ CMOS process parameters were used. The CMOS implementation of DX-MOCCII is shown in Figure 3 [13]. The aspect ratios of the CMOS transistors of the DXMOCCII are listed in Table 2. DC supply voltages of $\pm 1.8 \mathrm{~V}$ and biasing voltage of $V_{B B}=-0.7 \mathrm{~V}$ were used. The proposed circuit of Figure 2 was designed with $R=1 \mathrm{k} \Omega$ and $C=25 \mathrm{pF}$ to obtain a pole frequency of $6.36 \mathrm{MHz}$. The gain and phase responses are shown in Figure 4, where a phase shift of $90^{\circ}$ at a pole frequency of $6.27 \mathrm{MHz}$ is obtained, which is close to the theoretical designed value. The time-domain input and output responses of the circuit at the pole frequency are shown in Figure 5. Also, the Fourier spectrum of input signal and output signal is shown in Figure 6. Next, the amplitude of the input sinusoidal signal is varied from $0.1 \mu \mathrm{A}$ to $1000 \mu \mathrm{A}$, and the total harmonic distortion (THD) curve is plotted at a pole frequency of $6.36 \mathrm{MHz}$ and is shown in Figure 7.

\section{Conclusion}

In this paper, a new current-mode cascadable all-pass filter is presented. The proposed circuit uses single DX-MOCCII, a grounded resistor, and a grounded capacitor, which is the minimum component realization for an active $\mathrm{RC}$ filter circuit. The circuit requires no matching constraints and low active and passive sensitivities and employs grounded passive components only, which makes it suitable for integrated circuit implementation. The circuit also exhibits the feature of low-input impedance and high-output impedance. The PSPICE simulation results of the proposed circuit are in good agreement with the theoretical results.

\section{Acknowledgment}

The authors are thankful to the academic editors for recommending this paper.

\section{References}

[1] C. Toumazou, F. J. Lidgey, and D. G. Haigh, Analog IC Design: The Current-Mode Approach, Peter Peregrinus, London, UK, 1990.

[2] M. Higashimura and Y. Fukui, "Realization of current mode allpass networks using a current conveyor," IEEE Transactions on Circuits and Systems, vol. 37, no. 5, pp. 660-661, 1990.

[3] I. A. Khan, P. Beg, and M. T. Ahmed, "First order current mode filters and multiphase sinusoidal oscillators using CMOS MOCCIIs," Arabian Journal for Science and Engineering, vol. 32, no. 2, pp. 119-126, 2007.

[4] S. Minaei and E. Yuce, "All grounded passive elements currentmode all-pass filter," Journal of Circuits, Systems and Computers, vol. 18, no. 1, pp. 31-43, 2009.

[5] M. Higashimura, "Current-mode allpass filter using FTFN with grounded capacitor," Electronics Letters, vol. 27, no. 13, pp. 1182$1183,1991$.

[6] S. Maheshwari and I. A. Khan, "Novel first order all-pass sections using a single CCIII," International Journal of Electronics, vol. 88, no. 7, pp. 773-778, 2001.

[7] S. Minaei and M. A. Ibrahim, "General configuration for realizing current-mode first-order all-pass filter using DVCC," International Journal of Electronics, vol. 92, no. 6, pp. 347-356, 2005.

[8] S. Maheshwari, "Novel cascadable current-mode first order allpass sections," International Journal of Electronics, vol. 94, no. 11, pp. 995-1003, 2007.

[9] A. Toker, S. Özoguz, O. Çiçekoglu, and C. Acar, "Current-mode all-pass filters using current differencing buffered amplifier and a new high-Q bandpass filter configuration," IEEE Transactions on Circuits and Systems II, vol. 47, no. 9, pp. 949-954, 2000.

[10] S. Kilinç and U. Çam, "Current-mode first-order allpass filter employing single current operational amplifier," Analog Integrated Circuits and Signal Processing, vol. 41, no. 1, pp. 47-53, 2004.

[11] S. Minaei and E. Yuce, "Unity/variable-gain voltage-mode/current-mode first-order all-pass filters using single dual-X 
second-generation current conveyor," IETE Journal of Research, vol. 56, no. 6, pp. 305-312, 2010.

[12] P. Beg, M. A. Siddiqi, and M. S. Ansari, "Multi output filter and four phase sinusoidal oscillator using CMOS DX-MOCCII," International Journal of Electronics, vol. 98, no. 9, pp. 1185-1198, 2011.

[13] A. Zeki and A. Toker, "The dual-X current conveyor (DXCCII): a new active device for tunable continuous-time filters," International Journal of Electronics, vol. 89, no. 12, pp. 913-923, 2002.

[14] A. Zeki and A. Toker, "DXCCII-based tunable gyrator," International Journal of Electronics and Communications, vol. 59, no. 1, pp. 59-62, 2005.

[15] S. Minaei, "Electronically tunable current-mode universal biquad filter using dual-X current conveyors," Journal of Circuits, Systems and Computers, vol. 18, no. 4, pp. 665-680, 2009.

[16] S. Maheshwari and S. Maheshwari, "Multi input multi output biquadratic universal filter using Dual-X Current Conveyor (DXCCII)," in Proceedings of the International Conference on Computer and Communication Technology (ICCCT '10), pp. 626-629, September 2010.

[17] S. Maheshwari and B. Chaturvedi, "High-input low-output impedance all-pass filters using one active element," IET Circuits, Devices and Systems, vol. 6, no. 2, pp. 103-110, 2012.

[18] S. Maheshwari and M. S. Ansari, "Catalog of realizations for DXCCII using commercially available ICs and applications," Radioengineering, vol. 21, pp. 281-289, 2012.

[19] M. Bhusan and R. W. Newcomb, "Grounding of capacitors in integrated circuits," Electronic Letter, vol. 3, pp. 148-149, 1967.

[20] A. Fabre, O. Saaid, and H. Barthelemy, "On the frequency limitations of the circuits based on second generation current conveyors," Analog Integrated Circuits and Signal Processing, vol. 7, no. 2, pp. 113-129, 1995. 

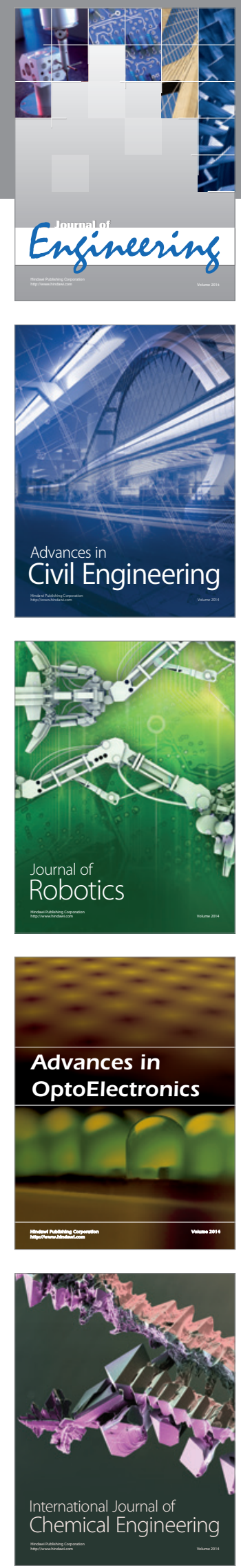

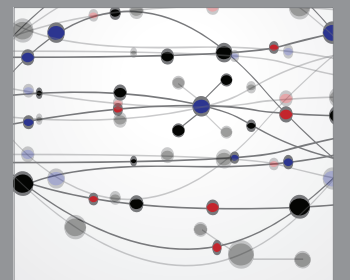

The Scientific World Journal
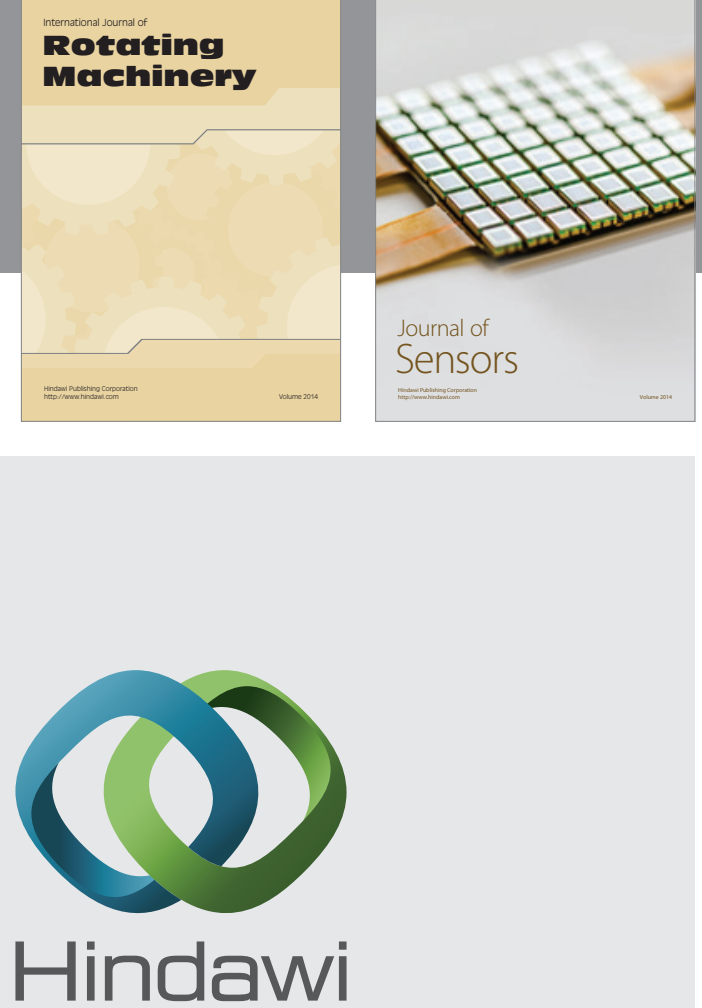

Submit your manuscripts at http://www.hindawi.com
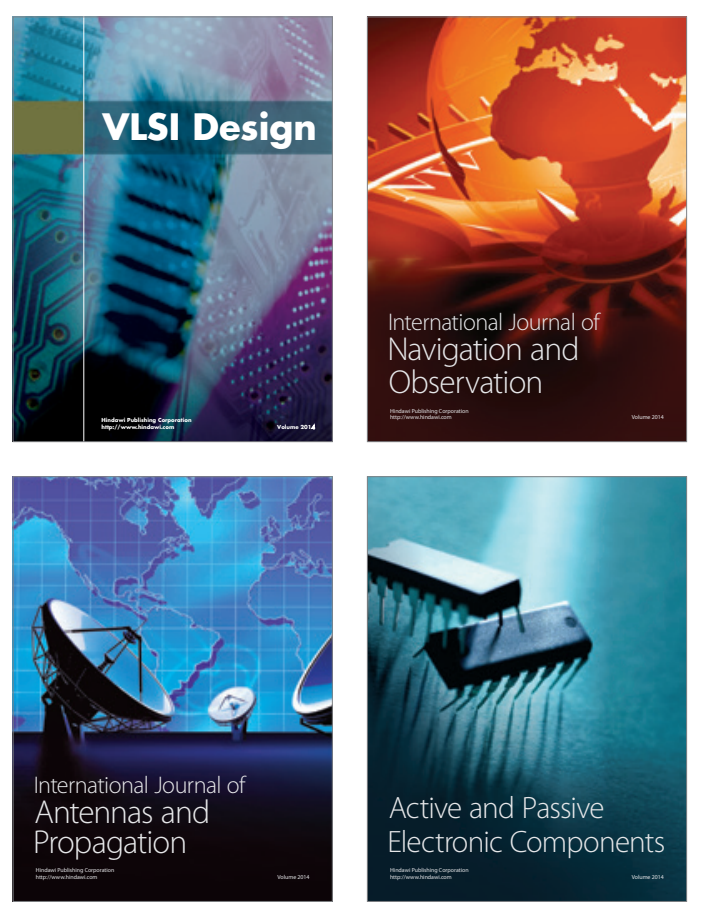
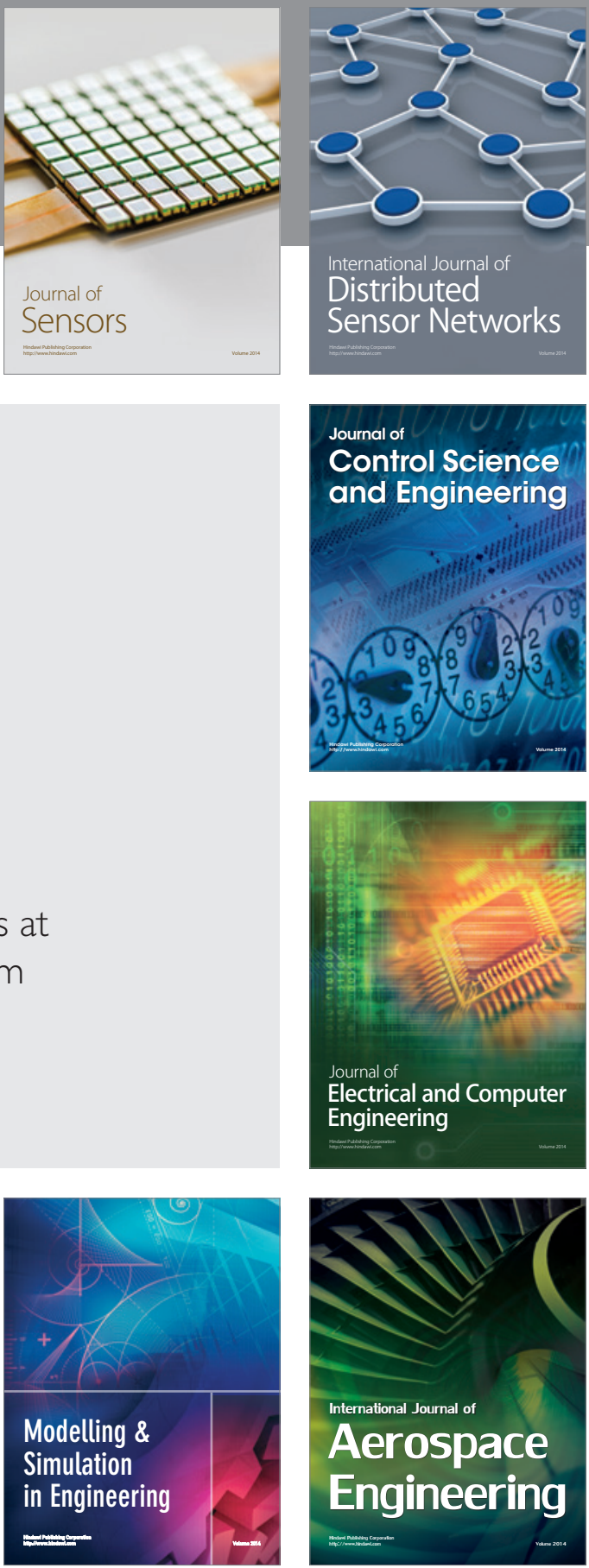

Journal of

Control Science

and Engineering
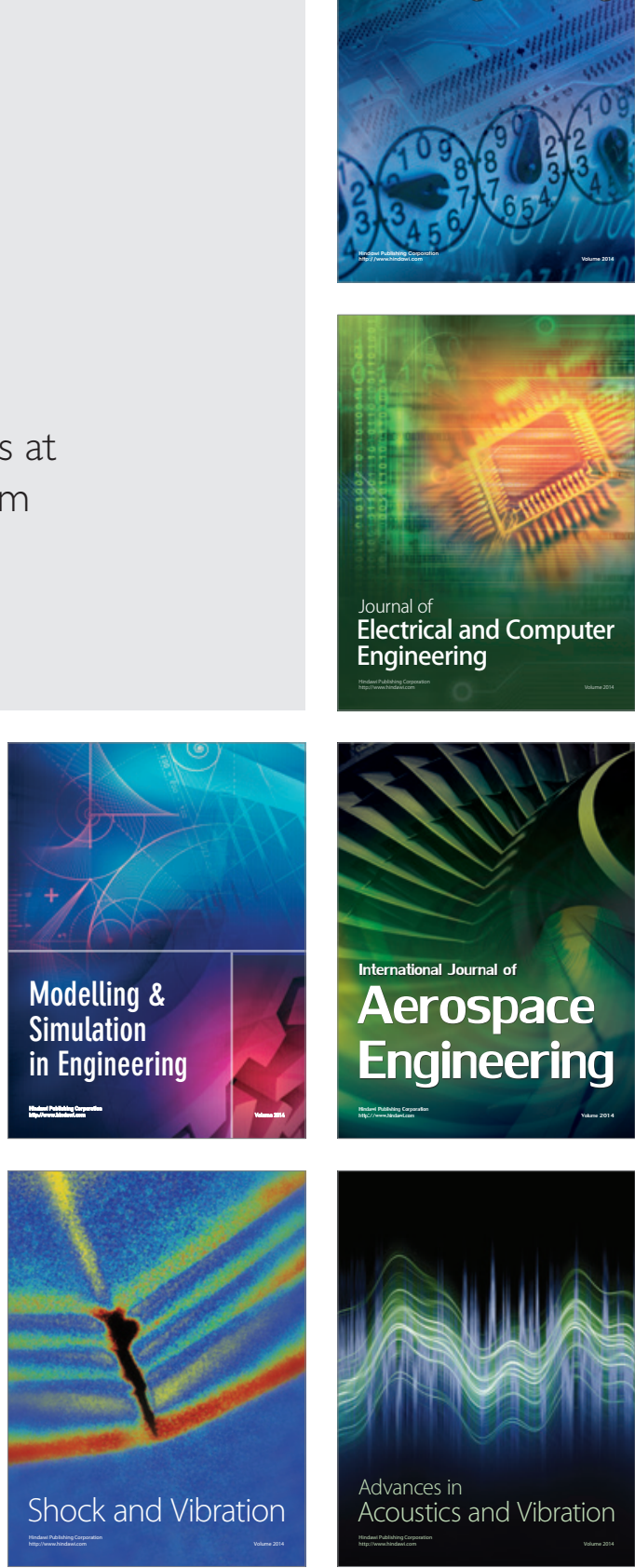